\title{
Optimal Timing of TV Commercials: Symmetrical Model
}

\author{
Tomáš Kadlec \\ CERGE-EI
}

January 2002

\begin{abstract}
In this paper I study the behavior of free-good producers (TV broadcasters) on a market where every consumer (TV viewer) perpetually makes a decision whether to consume and which product (TV channel) to consume contingent on the attractiveness of the currently consumed product. Every producer optimally allocates a time period where a product with higher attractiveness (TV program) is replaced by a product with lower attractiveness (advertising). While products with higher attractiveness represent producers' costs, products with lower attractiveness bring in revenue that is proportional to the audience reach. I assume that consumers choose among products and the outside option following a Markov process where probabilities of transition reflect various attractiveness of the products. Given symmetrical positions of the producers, I prove that their optimal strategy is to put their commercial breaks into the same or very close times. For some setting of the parameters, the breaks will overlap perfectly. Given the perfect overlap, both broadcasters are better off if they fragment their breaks into shorter breaks keeping the total amount of commercial time the same.

V tomto clánku studuji chování televizních stanic na trhu sledovanosti, kde se každý divák rozhoduje zda a kterou stanici sledovat $\mathrm{v}$ závislosti na atraktivite práve sledovaného programu. Každá z televizních stanic optimálne vybírá, ve kterém case produkt s vyšší atraktivitou (televizní program) nahradit produktem s nižší atraktivitou (reklama). Zatímco televizní program predstavuje náklad pro televizní stanici, reklama je zdrojem príjmu, které jsou úmerné její sledovanosti. Predpokládám, že diváci se pohybují mezi jednotlivými kanály a stavem, kdy televizi nesledují, náhodne podle Markovova procesu, ve kterém pravdepodobnosti prechodu odrážejí atraktivitu daného programu. Pokud jsou na thu dve stanice a mají symetrické postavení, jejich optimální strategií je takové nacasování reklamy, pri kterém se jejich reklamní bloky prekrývají. Pro urcité nastavení parametru je optimální prekryv 100\%-ní. Pri takovém prekryvu by navíc televizní stanice mely rozdelit svuj celkový reklamní cas do co nejmenších bloku.
\end{abstract}

Acknowledgements: I am especially grateful to Prof. Avner Shaked for his critical and useful comments. The usual disclaimer applies.

Address: CERGE-EI, Politických veznu 7, 11121 Prague, Czech Republic. E-mail: tomas.kadlec@ cerge-ei.cz CERGE-EI is a joint workplace of the Center for Economic Research and Graduate Education, Charles University, and the Economics Institute of the Academy of Sciences of the Czech Republic. 


\section{Introduction}

Nowadays, almost all the goods we buy are not produced by a craftsman in our neighborhood but by a number of variously distant producers. Thus, we do not know the producers personally and each of them needs to persuade us to buy his or her particular product. Advertising is a traditional direct way of such a persuasion. As television became the most frequent medium of information and entertainment, it also became the most influential medium of advertising. TV broadcasters operate on two markets. The first one is the advertising market on which they sell their commercial time. The second one is the audience market on which they strive for viewers. On both markets the TV broadcasters compete with each other, as well as with other advertising media; e.g., internet, newspapers, radio. Note that the two markets are linked together; i.e., the higher audience watches a channel, the higher impact of the advertising on this channel and thus the higher price advertisers are willing to pay for their spots.

Setting the price, the timing and the amount of commercials represents a complicated game. This paper focuses on the final decision broadcasters make in this game; i.e., the timing of their breaks relative to the competitors' breaks. A brief remark on commercial time fragmentation will also be made. Hence, this paper shows that given a fixed amount of commercial time, broadcasters are better off if they divide the current commercial time into shorter but more frequent breaks and coordinate the timing of these breaks.

The paper is organized as follows. In Section 1 I explain intuition behind the model, show an example of legal framework and review the literature. In Section 2 a twoperiod symmetric model is presented. In Section 3 I describe a general continuous-time 
model and in Section 4 the model is solved for 2 symmetric broadcasters. In Section 5 I make a remark on commercial time fragmentation and in Section 6 I conclude the paper.

\subsection{Intuition behind the Model}

The model is based on the very simple and intuitive assumption that viewers prefer watching a TV program to watching advertising and that the longer a commercial break is, the fewer people watch it. TV broadcasters are aware of this and thus attract viewers by programs, which represent broadcasters' costs, and interrupt the programs by advertising which bring in revenue.

Of course, the audience reach of a given channel depends also on the attractiveness of competitors' programs. This raises an interesting question whether the TV stations should place their commercial breaks into the same times; i.e., whether there is an equilibrium period when all the broadcasters on the market air their commercials. The theoretical result presented below is more complicated and depends on the parameters of the model.

One can object to the idea that TV broadcasters can set the length of commercial breaks such that it maximizes their revenue. The legal system usually imposes limitations on the amount of advertising aired during a TV program. Naturally, we can expect that this limit is shorter than the amount of commercials optimally chosen by the broadcasters. Such limitations obviously increase the price of advertising and make the broadcasters' decision process simpler; i.e., they have to decide about the optimal broadcasting time only. On the market there is usually a public-service broadcaster, a state body that bears certain social functions and that is more restricted in advertising than commercial 
broadcasters. The social function can be considered as a restriction on the attractiveness

of the broadcaster's program. Naturally, we can ask how much revenue the public-service broadcaster loses due to restrictions on its advertising and programming. This asymmetry is an interesting topic for research; however, this paper focuses on the symmetrical position of the broadcasters.

\subsection{Legal Framework}

As mentioned above, broadcasters on TV markets are legally restricted. I will demonstrate these restrictions in the following summary of the Czech legal framework as it is described in Act No. 468/1991. The law classifies broadcasters into public-service broadcasters and licensed commercial broadcasters. While there is one state organization operating two channels as the public-service broadcaster on the Czech TV market, there are more commercial broadcasters and their number grows.

The public-service broadcaster must not allocate more than $1 \%$ of total broadcasting time to advertising, and in the time period from 7 p.m. to 10 p.m. advertising must not exceed 6 minutes in one hour. The total advertising time can be expanded up to a total of $10 \%$ by airing direct offers to sell, buy or rent goods and services (TV shopping) with a limit of one hour a day. Commercial broadcasters' advertising time is limited by $10 \%$ of the total broadcasting time that can be expanded up to $20 \%$ by TV shopping. Total advertising time on a commercial channel must not exceed 12 minutes in any hour and TV shopping must not exceed one hour a day. 


\subsection{Literature Review}

There is very little economic literature published on timing of commercials. Fortunately, some relevant sources can be found in operations research and management science literature. Some papers like Gabszewicz, Laussel and Sonnac (1999) focus on some aspects of TV broadcasters' behavior but the only work modeling timing of commercials, I found, was Epstein (1998). Nevertheless, the assumptions of my model are different from Epstein's and my modeling approach is original.

Gabszewicz, Laussel and Sonnac (1999) produced an interesting paper on the competition of TV broadcasters. Unlike my paper, they focus on program competition and length of the commercials in a three-stage game. They assume that there exist two types of programming (e.g., entertainment and culture), each viewer has his own most favorite mixture of these types and there are two channels on the market. Thus the two broadcasters have to determine an optimal mixture of their programs. This Hotteling-type competition predicts that the two channels always mix their programs, the mixtures are different and the viewers can be classified into three groups. One group of viewers only watch channel 1, another group of viewers only watch channel 2 and the third group watches a combination of both. Regarding the length of commercials, they introduce advertising saturation level as an exogenous variable such that if the length of commercials exceeds this level, viewers don't watch the channel at all. Finally they prove that the broadcasters set the amount of commercials equal to this saturation level.

Some assumptions of Gabszewicz, Laussel and Sonnac (1999) do not seem to be realistic. For instance, I find the saturation level of viewers to be an artificial instrument to obtain reasonable results. Obviously, no such level exists, as there are infomercials on 
some markets. The infomercials air commercials only and have positive audience reach. This instrument can be interpreted as a need for state regulations; given the setting of the model and no saturation level the broadcasters will air purely commercials and thus the channels will become infomercials. They also assume that viewers are uniformly distributed on an interval $[0,1]$ where 0 represents willingness to watch entertainment only and 1 willingness to watch culture only. The results would be more convincing if they can be shown to be robust for other settings.

Epstein (1998) focuses on the same question as this paper; i.e., the timing of commercials of two competing channels. He sets up a model where broadcasters' payoffs are determined by the average number of viewers watching the channel and this number is a linear function of the starting and ending times of the commercials. Under these simplified and linearized assumptions, he proves that broadcasters' optimal strategy is perfect cooperation; i.e., perfect overlap of their commercials. Epstein supports his theoretical findings by an empirical analysis studying four U.S. networks (NBC, ABC, CBS, and FOX). The null hypothesis that all the networks break for commercials at the same time cannot be rejected.

The theoretical part of Epstein's paper contains assumptions that can be criticized. For example, the assumption that an infomercial channel would not be watched by any viewers is not realistic. Furthermore, the broadcasters' payoff function is rather simple and seems to be constructed just to give the expected results. Nevertheless, these simplifications, although unrealistic, give intuitive and straightforward results which are supported by the empirical study. While Epstein creates the broadcasters' payoff function 
artificially, I derive the payoff from the number of viewers watching the commercials, assuming that viewers choose among the channels following a Markov process.

\section{Symmetric 2-Period Model}

First, a symmetric 2-period model will be presented. The purpose of this model is to illustrate the concept applied in this paper in a simple environment, and thus, to provide a better insight into a more sophisticated model in Section 3.

\subsection{Set up: Markov Process in Discrete Time}

Let's assume a discrete-time model with 2 TV broadcasters and a large population of agents (viewers). The viewers can be in 3 states; i.e., each of them is watching one of 2 channels (states 1 and 2) or not watching TV at all (state 0 ). The broadcasting scheme of both channels consists of TV programs and commercials. After a TV program there is always a commercial break and vice versa. The length of the TV program and the commercial break are the same. Without loss of generality let this length be 1. Assume that the probabilities of switching from one state to another equal $p$ for state 0 and the channels broadcasting TV programs, and equal $r$ for the channels broadcasting commercials. Hence, the Markov probability matrices are

$$
\mathbf{P}_{\mathbf{n}}=\left(\begin{array}{ccc}
1-2 p & p & p \\
p & 1-2 p & p \\
p & p & 1-2 p
\end{array}\right)
$$

for the case of no commercials, 


$$
\mathbf{P}_{\mathbf{1}}=\left(\begin{array}{ccc}
1-2 p & p & p \\
r & 1-2 r & r \\
p & p & 1-2 p
\end{array}\right)
$$

for the case of a commercial break on TV1,

$$
\mathbf{P}_{2}=\left(\begin{array}{ccc}
1-2 p & p & p \\
p & 1-2 p & p \\
r & r & 1-2 r
\end{array}\right)
$$

for the case of a commercial break on TV2 and

$$
\mathbf{P}_{\mathbf{b}}=\left(\begin{array}{ccc}
1-2 p & p & p \\
r & 1-2 r & r \\
r & r & 1-2 r
\end{array}\right)
$$

for the case of commercial breaks on both TV1 and TV2. Let $0<p<r<0.5$; i.e., let all probabilities be well defined and viewers prefer watching TV programs to advertising.

Broadcasters' revenue is given by the audience reach of the commercial break. I assume that the block (TV program, commercials) or (commercials, TV program) repeats many times a day. Therefore, I consider a fixed-point distribution; i.e., the distribution at time $t$ is the same as the distribution at time $t+2$. The Markov process as defined above guarantees uniqueness of such a fixed point and fast convergence to it irrespective of the initial distribution. Under this setting, the problem reduces into a two-period model with a fixed-point distribution where the broadcasters have two options; to place TV programs and commercials into the same time units or to air the TV program during the competitor's commercial time.

The audience reach of one TV channel as a function of time is illustrated in Figure 1. Note that this figure is derived for the fixed-point distribution. Thus we can focus simply on the first two periods and study whether the opponent's best response is to 
do the same or to start with a commercial break in the first period and follow with a TV program.

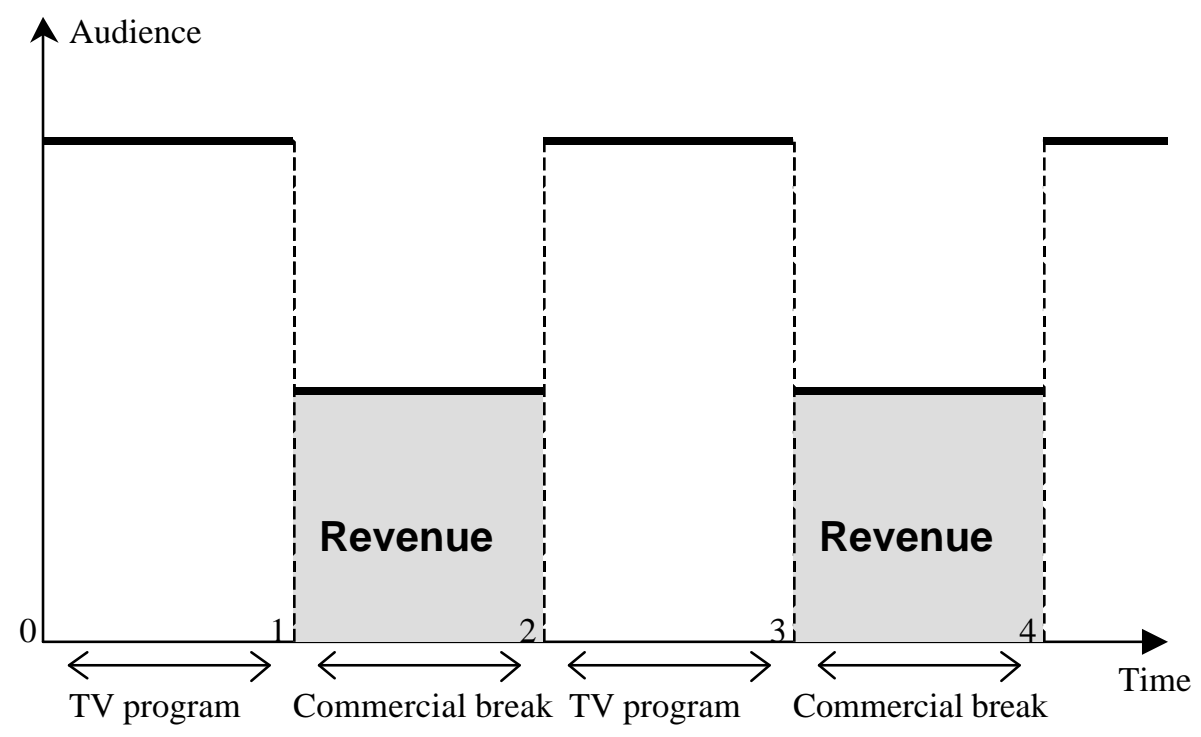

\section{Figure 1}

\subsection{Solution to the Discrete-Time Symmetric Model}

As was discussed above, we focus on comparing only two cases. The first one is perfect coordination; i.e., both channels broadcast commercials at the same time. In Figure 1, this corresponds to a situation where both stations air TV program during odd units and commercials during even units. The second case is a contra strategy; i.e., the commercial breaks do not overlap. In Figure 1, this corresponds to a situation where one station airs commercials during even units and the other during odd units.

The model is symmetric and so are the payoffs. The payoff of each TV broadcaster in perfect coordination case is

$$
\frac{p(-2+2 p+r)}{6 p^{2}-r+p(-5+3 r)}
$$


while in the contra strategy case the payoff is

$$
\frac{p(2-3 r)}{-3 p^{2}+r+p(5-6 r)} \text {. }
$$

The difference perfect coordination - contra strategy equals

$$
\frac{p(2-3 p)(r-p)(2 p+r)}{(r+p(5-6 p-3 r))(r+p(5-3 p-6 r))}
$$

Given $0<p<r<0.5$, the difference is a quotient of two products of positive numbers; hence, the difference is positive too. Therefore, perfect coordination is the optimal strategy of both channels.

\section{General Model in Continuous Time}

In this section, a general continuous-time model for $n$ broadcasters is presented. Unfortunately, this model cannot be solved in this general set-up because it leads to too extensive and inconclusive formulas. Therefore, it is solved in Section 4 in a symmetric set-up for 2 channels.

\subsection{Viewers' Behavior as a Markov Process in Continuous Time}

Let's assume that there are $n$ TV broadcasters on the market and a large population of agents (viewers) who can be in $n+1$ states; i.e., each of them is watching one of $n$ channels (states $1, \ldots, n$ ) or not watching TV at all (state 0 ). The key assumption of my model is that the numbers of agents in particular states change over time as if the agents follow a homogeneous Markov process in continuous time. Denote $S(t)$ as the state of a specific agent at time $t, p_{i, j}$ as the probability of transition from state $i$ to state $j$ and $q_{i, j}$ as the transition rate from state $i$ to state $j$; i.e., 


$$
\begin{gathered}
p_{i, j}(\Delta t)=\mathrm{P}[S(t+\Delta t)=j \mid S(t)=i], i, j=0, \ldots, n, \\
q_{i, j}=p_{i, j}^{\prime}\left(0_{+}\right)=\lim _{\Delta t \rightarrow 0_{+}} \frac{p_{i, j}(\Delta t)-p_{i, j}(0)}{\Delta t} .
\end{gathered}
$$

Hence,

$$
\forall_{i \in\{0,1, \ldots, n\}} \quad q_{i, i}=-\sum_{\substack{j=0 \\ j \neq i}}^{n} q_{i, j} .
$$

Let $\mathbf{P}(t)=\left(p_{i, j}(t)\right)$ be the matrix of probabilities, $\mathbf{Q}=\left(q_{i, j}\right)$ be the matrix of rates and $\mathbf{d}(t)$ be the distribution of agents among states at time $t$. Then,

$$
\dot{\mathbf{d}}(t)=\mathbf{Q}^{\mathbf{T}} \cdot \mathbf{d}(t)
$$

defines the system of differential equations. The solution is

$$
\mathbf{d}(t)=\left(\mathrm{e}^{\mathbf{Q} \cdot t}\right)^{\mathrm{T}} \cdot \mathbf{d}(0)=\mathbf{V} \cdot \operatorname{Diag}\left\{e^{\lambda_{1} \cdot t}, e^{\lambda_{2} \cdot t}, \ldots, e^{\lambda_{n+1} \cdot t}\right\} \cdot \mathbf{V}^{-1} \cdot \mathbf{d}(0),
$$

where $\mathbf{V}$ is a matrix formed by the eigenvectors of $\mathbf{Q}^{\mathbf{T}}, \lambda$ 's are corresponding eigenvalues and Diag stands for a diagonal matrix. ${ }^{1}$

\subsection{Advertising}

Assume that at time $t$ the distribution of viewers among states is given by vector $\mathbf{d}(t)$ and that a commercial break starts on channel $k$. Thus, the viewers will leave this channel at higher rates; i.e., there will be new rates $\tilde{q}_{i, j}$ such that $\left|\tilde{q}_{k, j}\right| \geq\left|q_{k, j}\right|$ and $\tilde{q}_{i, j}=q_{i, j}$ for $i \neq k$. This will lead to continuous decline in the audience reach of channel $k$ unless the parameters change; e.g., channel $k$ stops the commercial break or another channel starts airing commercials.

\footnotetext{
${ }^{1}$ See Appendix I.
} 
Assume that the price of one commercial time unit is proportional to the number of viewers watching it. Hence, TV broadcasters' revenue maximization can be considered as the maximization of the audience watching commercials. There are two natural ways we can define broadcasters' revenues from a commercial break. The first is an integral over the number of viewers watching the channel from the start of the commercial break until its end; let's call it integral payoff. The second is the length of the commercial break multiplied by the minimum audience reach during this break; let's call it minimum payoff. The integral payoff means that either the price of advertising differs within one commercial break, which is not realistic, or that the price is determined by the average audience reach. Thus, some advertiser would pay for more viewers than would actually watch their ads. On the other hand, the minimum payoff approach implies that the price is the same for all ads within one block and each advertisement is watched by at least as many viewers as corresponds to its price. $^{2}$

Integral and minimum payoffs are illustrated in Figure 2. While area A represents minimum payoff, integral payoff is represented by area $\mathbf{A}+\mathbf{B}$. Due to the aspects of the integral payoff stated above, I assume in this paper that the price of advertising is defined by the minimum payoff. Comparing our results with the integral payoff approach may be an interesting issue for future research.

\footnotetext{
${ }^{2}$ The minimum payoff is also consistent with a more advanced setting where viewers can learn the timing of commercials and thus adjust. By adjusting I mean that viewers who leave a commercial break in the middle are better off if they leave immediately at the start of the break and return when the commercials are over. That means that all commercials within one break are watched by an equal number of viewers.
} 


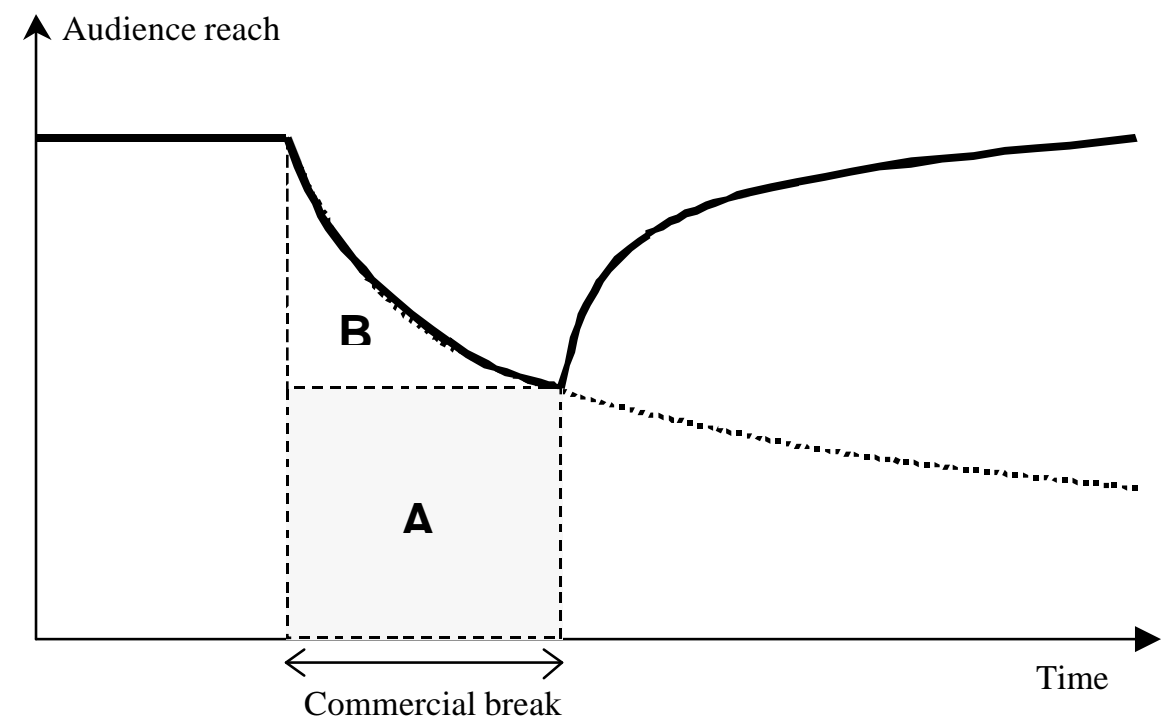

Figure 2

Of course, this is just the simplest illustration of a broadcaster's behavior under the unchanged parameters of the other channels. The purpose of my model is to study the dynamics of the system if more broadcasters start their advertising blocks at the same or very close times.

\section{Solution to the Symmetric Model in Continuous Time}

\subsection{Set-up of the Model}

Assume that $n=2$; i.e., there are two TV broadcasters on the market and thus the viewers can be in one of three states: not watching TV, watching TV1, or watching TV2. Assume that all transition rates among states equal $p$ if there are no commercials and that they are $k$-times higher for the channel broadcasting commercials. Hence, the matrices of transition rates are 


$$
\mathbf{Q}_{\mathbf{n}}=\left(\begin{array}{ccc}
-2 p & p & p \\
p & -2 p & p \\
p & p & -2 p
\end{array}\right)
$$

for the case of no commercials,

$$
\mathbf{Q}_{\mathbf{1}}=\left(\begin{array}{ccc}
-2 p & p & p \\
k p & -2 k p & k p \\
p & p & -2 p
\end{array}\right)
$$

for the case of a commercial break on TV1,

$$
\mathbf{Q}_{2}=\left(\begin{array}{ccc}
-2 p & p & p \\
p & -2 p & p \\
k p & k p & -2 k p
\end{array}\right)
$$

for the case of a commercial break on TV2 and

$$
\mathbf{Q}_{\mathbf{b}}=\left(\begin{array}{ccc}
-2 p & p & p \\
k p & -2 k p & k p \\
k p & k p & -2 k p
\end{array}\right)
$$

for the case of commercial breaks on both TV1 and TV2. Let $p>0$ and $k>1$; i.e., let transition rates be positive and viewers prefer TV programs to advertising.

Further assume that the broadcasters place their commercial breaks of length $L$ into a time interval $T$ and they repeat the same action for every interval; naturally, $0<L<T$. Without loss of generality, let TV1 start its commercial breaks at time $0, T, 2 T, 3 T, \ldots$. TV2 can place its commercial break overlapping the commercial break of TV1 or after it. The aim is to study the environment in the long run when the process reaches its fixed point. Hence, we can focus our analysis on one cycle of length $T$ where the distribution of viewers at time 0 equals the distribution at $T$. For fixed parameters $p, k, L, T$, such a distribution exists, is unique and the system converges to it irrespective of the starting 
distribution. ${ }^{3}$ The idea of a fixed point is necessary because the time between two commercial breaks is not sufficient for the process to converge to its stationary levels and we assume that the broadcasters repeat the same action each cycle. Imagine, for instance, that a broadcaster airs 18 minutes of a program followed by 2 minutes of commercials. This program scheme is fixed and repeated forever, then, $T=20$ and $L=2$.

Next, I will analyze the optimal timing of commercials. For this purpose, I need to distinguish two cases. First, I will consider the no overlapping case where TV2 starts its commercial break after the end of TV1's commercials; thus, the breaks do not overlap. Second, I will focus on the overlapping case where the two breaks overlap at least partially.

\subsection{No overlapping}

TV1's commercial break lasts from time 0 to time $L$ and TV2's commercials start at time $L+t$ and end at $2 L+t$. In other words, TV2's commercials start $t$ after the end of TV2's commercials. Let's find the optimal $t$ for both TV's. Denote

$$
\mathbf{M}_{\mathbf{i}}(s)=e^{s \cdot \mathbf{Q}_{\mathrm{i}}^{\mathrm{T}}}, \text { for } \mathrm{i} \in\{\mathrm{n}, 1,2, \mathrm{~b}\} .
$$

Then, the distribution $\mathbf{d}(0)$ at time 0 must satisfy

$$
\mathbf{M}_{\mathbf{n}}(T-2 L-t) \cdot \mathbf{M}_{2}(L) \cdot \mathbf{M}_{\mathbf{n}}(t) \cdot \mathbf{M}_{\mathbf{1}}(L) \cdot \mathbf{d}(0)=\mathbf{d}(0) .
$$

Analogously, we could derive all $\mathbf{d}(s)$ for $0<s<T$.

Considering the minimum payoff approach, TV1's revenue equals $d_{2}(L) . L$ and TV2's revenue is $d_{3}(2 L+t) . L$.

\footnotetext{
${ }^{3}$ Just imagine the system as a Markov process in discrete time where one time unit corresponds to our cycle of length $T$. The probability matrix is well defined and the process is homogeneous, finite and irreducible; thus, the stationary distribution exists and is unique. The convergence is satisfied as well.
} 


$$
\frac{\partial\left(d_{2}(L) \cdot L\right)}{\partial t}=\frac{-4 e^{4 L p+3 p t}\left(e^{L p(1+2 k)}-1\right)\left(e^{3 p T}-1\right)(k-1) p L}{(1+2 k)\left(-4 e^{4 L p}+6 e^{p(2 L(1+k)+3 T)}+e^{4 L p+3 p T}+e^{4 k L p+3 p T}-4 e^{4 k L p+6 p T}\right)}
$$

Obviously, the numerator is negative. It can be shown that the denominator is negative ${ }^{4}$ too. Hence, the first derivative of TV1's revenue with respect to $t$ is positive. That means the greater $t$ the higher TV1's revenue. However, $0<t<T-2 L$. Therefore, the optimal strategy for TV1, given that the commercial breaks do not overlap, is to place its commercial break just after TV2's commercials.

$$
\frac{\partial\left(d_{3}(2 L+t) \cdot L\right)}{\partial t}=\frac{4 e^{p(3 T-2 L-3 t)}\left(e^{L p(1+2 k)}-1\right)\left(e^{3 p T}-1\right)(k-1) p L}{(1+2 k)\left(-4 e^{4 L p}+6 e^{p(2 L(1+k)+3 T)}+e^{4 L p+3 p T}+e^{4 k L p+3 p T}-4 e^{4 k L p+6 p T}\right)}
$$

No doubt, the numerator is positive. The denominator equals the previous denominator; hence, the derivative is negative. Thus, the optimal strategy for TV2, given that the commercial breaks do not overlap, is to place its commercial break just after TV1's commercials.

The result given above is intuitive. See Figure 3. As $t$ decreases, the beginning of TV2's advertising block gets closer to the end of TV1's commercials, TV2's audience during commercials increases; thus, TV2's revenue (shaded area in the graph) increases. Analogously, TV1's advertising block gets further from the end of TV2's commercials, ${ }^{5}$ TV1's audience during commercials declines; thus, TV1's revenue declines. This intuition does not take into account the shift of the fixed-point distribution; i.e., the distribution at time 0 is not considered to be affected by $t$. Of course, the formulas above were calculated rigorously and they include the impact of a change in $t$ on the fixed-point distribution.

\footnotetext{
${ }^{4}$ See Appendix II.

${ }^{5}$ Note that the cycle of length $T$ circulates and that time is relative here. Time 0 can be set arbitrarily; I set it as the beginning of TV1's commercial break.
} 


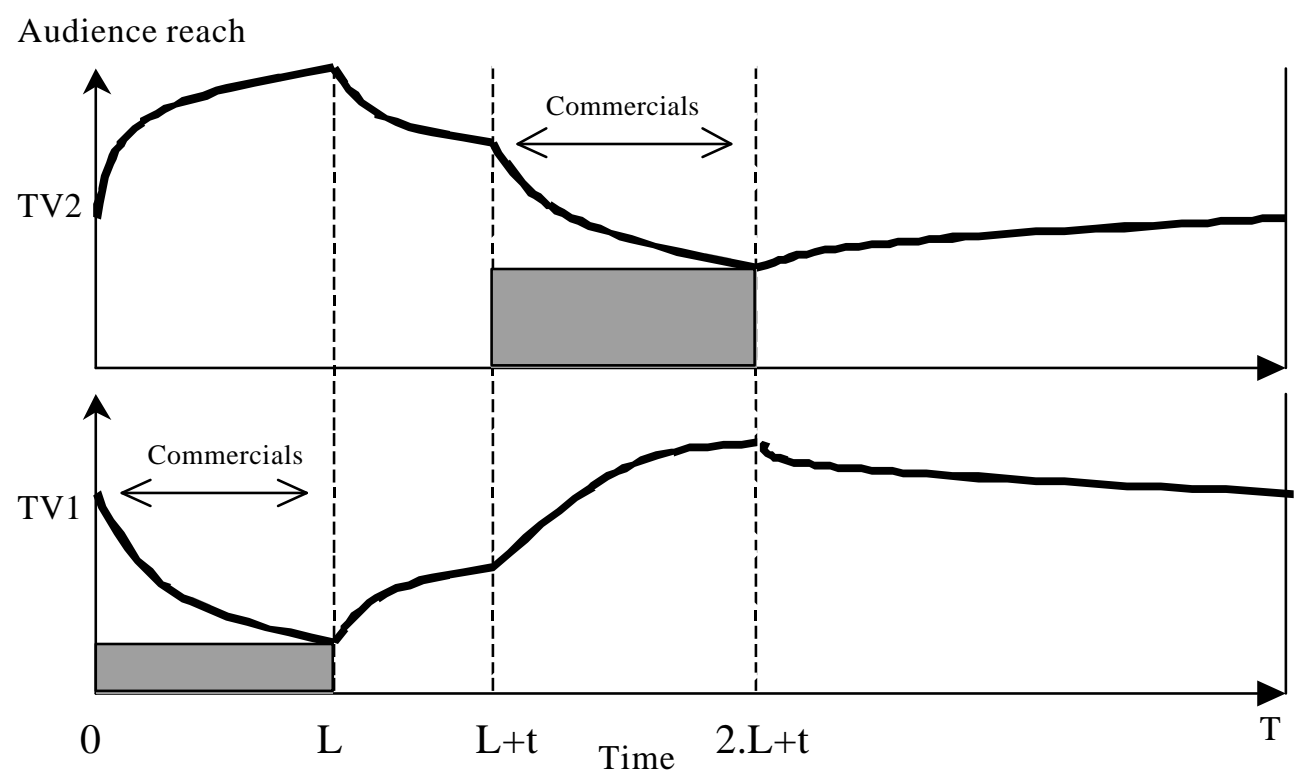

Figure 3

To sum up, assuming that the commercial breaks do not overlap, both TV broadcasters want to place their commercial breaks just after their competitor's commercials. It seems that the broadcasters tend to place their commercials into one time; i.e., they seem to be better off if their commercials overlap to a certain extent. Whether this conclusion is true and to what extent will be shown in the following section.

\subsection{Overlapping commercials}

TV1 starts its commercial break at time 0 and TV2 at time $t$, where $0<t<L$. This means that from time 0 to time $t$ only TV1 airs commercials, from time $t$ to time $L$ there are commercials on both channels, from time $L$ to time $L+t$ only TV2 broadcasts 
commercials and from $L+t$ to $T$ there are no commercials. Then, the distribution $\mathbf{d}(0)$ at time 0 must satisfy

$$
\mathbf{M}_{\mathbf{n}}(T-L-t) \cdot \mathbf{M}_{\mathbf{2}}(t) \cdot \mathbf{M}_{\mathbf{b}}(L-t) \cdot \mathbf{M}_{\mathbf{1}}(t) \cdot \mathbf{d}(0)=\mathbf{d}(0)
$$

Analogously we could derive all distributions $\mathbf{d}(s)$ for $0<s<T$.

Unfortunately, the formulas for TV1's and TV2's revenues and their first derivatives with respect to $t$ are too extensive. Therefore, it is not possible to conclude whether they are positive or negative and I do not present them here. However, I evaluated the derivatives for a large range of values and I observed the following:

1. The revenue of TV2 is a strictly decreasing function of $t$ on domain $[0, L]$.

2. The revenue of TV1 is either a decreasing function of $t$ or it has a unique local maximum at $t^{*}$ on domain $(0, L)$. Moreover, it appears that there exists a threshold $K$ such that for $k<K$ the revenue is a strictly decreasing function of $t$ and for $k>K$ there is a maximum at $t^{*}$. Figure 4 shows $^{6}$ the threshold $K$ as a function of transition rate $p$. The points in the graph above the line represent values $(p, k)$ for which TV1's optimal strategy is to place the commercial break $t^{*}$ before TV2's commercial, and points below the line represent values $(p, k)$ for which TV1's optimal strategy is a perfect overlap.

\footnotetext{
${ }^{6}$ The graph was derived for $T=20$ and $L=2$. This corresponds to a situation where a commercial break of 2 minutes repeats every 20 minutes; thus, commercials constitute $10 \%$ of total time. Note that the absolute values of $T, L$ and $p$ do not play any role; i.e., the results for setting $(T, L, p)$ are the same as for $(c . T, c . L$, $p / c$ ) where $c$ is an arbitrary positive constant. For any $(T, L)$ the graph of $K$ is a decreasing and convex function of $p$.
} 


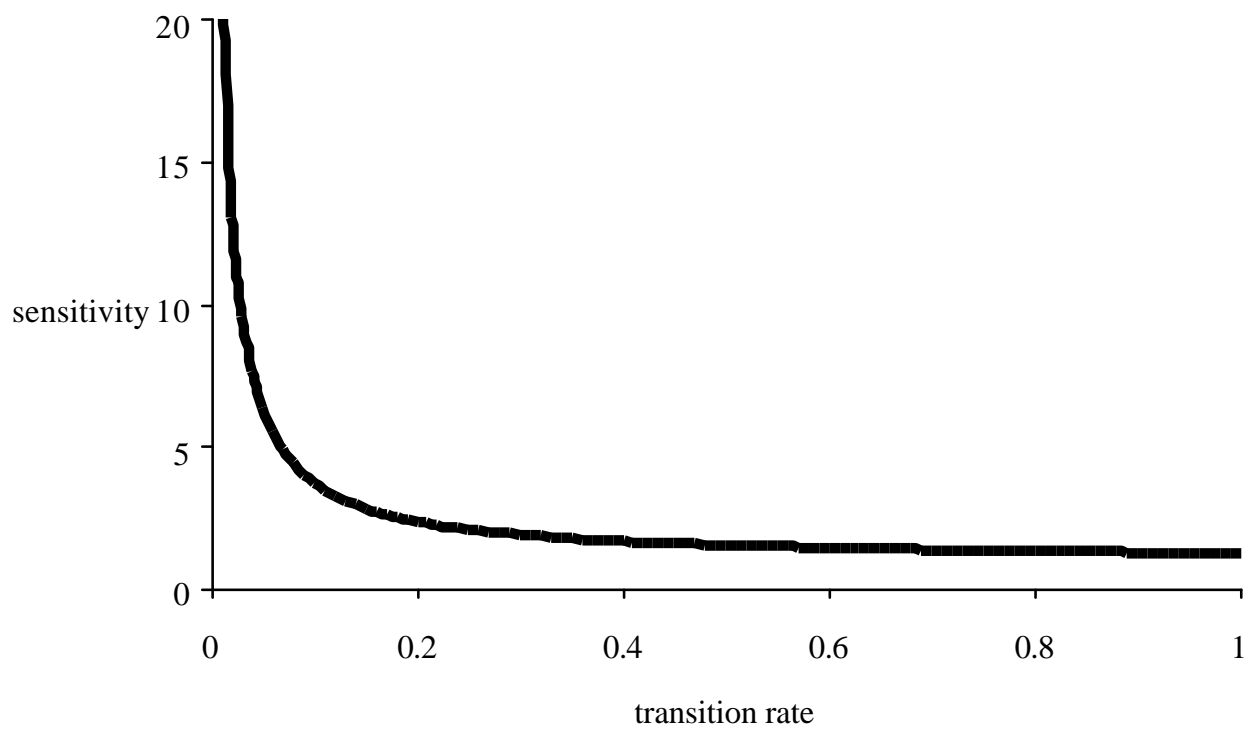

Figure 4

The intuition in the overlapping case does not follow the theoretical results as straightforwardly as if the commercials do not overlap. As illustrated in Figure 5, as TV2 starts its break closer to the beginning of TV1's commercial, it starts with a smaller audience reach but faces a more favorable regime (the audience decline is more severe if the other channel's commercials have already finished). The numerical result shows that the latter effect (a more favorable regime) preponderates the former (greater initial audience). As TV1 starts airing commercials at a time closer to the beginning of TV2's commercial break, it also faces a more favorable regime. However, there is a new aspect. If $k$ and $t$ are sufficiently high, the audience reach of TV1 at time $t$ is actually under a stationary level in the regime where both channels air commercials; thus, TV1's audience starts growing after $t$ although the commercials are being broadcast. That is why perfect overlap might not always be the optimal strategy, and the broadcaster is better off to start 
the commercials $t^{*}$ before its competitor. As in the no-overlapping case, this intuition does not take into account the shift of the fixed-point; i.e., the distribution at time 0 is not considered to be affected by $t$. However, the formulas above were calculated rigorously and they include the impact of a change in $t$ on the fixed-point distribution.

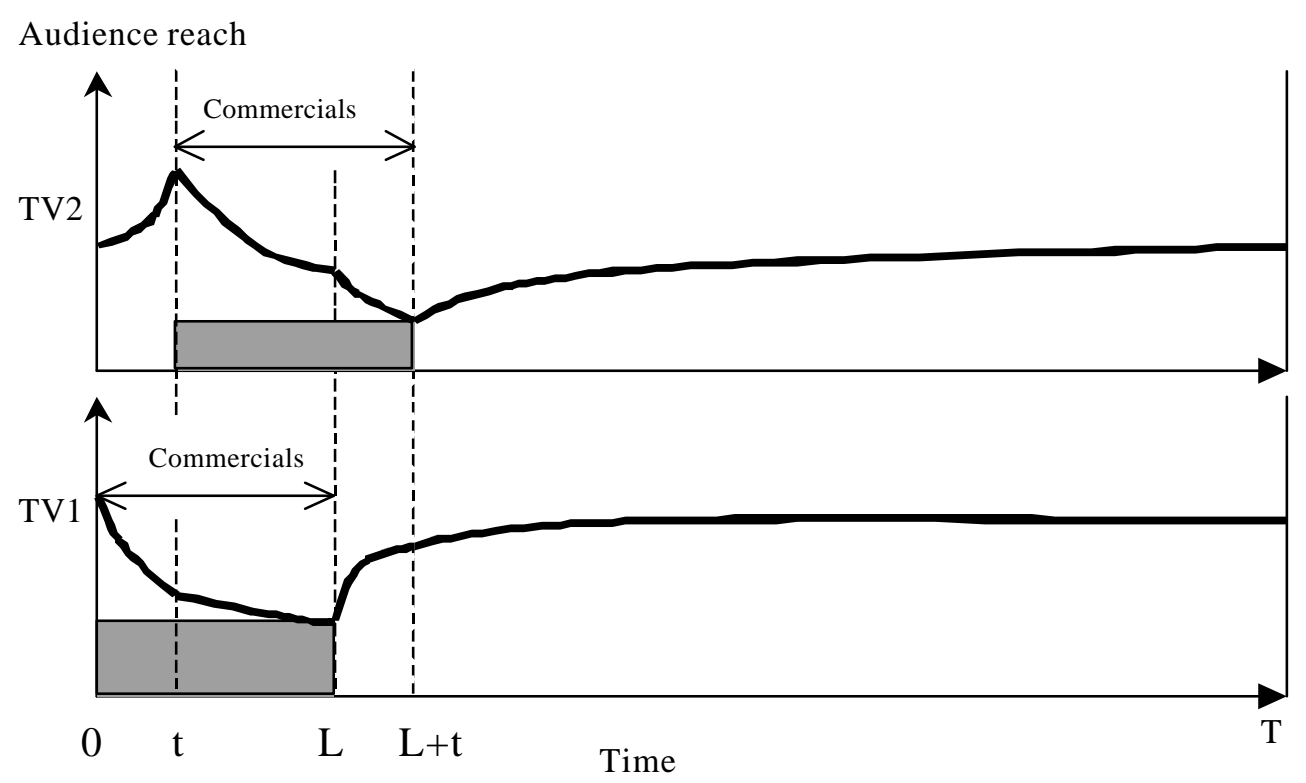

Figure 5

To sum up, if the viewers are less sensitive to advertising, and thus $k$ is small, the optimal timing of both broadcasters is a perfect overlap; i.e., they start at the same time and they are in equilibrium. However, there exists a sensitivity threshold $K$ such that if $k>K$, the optimal strategy is a partial overlapping where both broadcasters want to start $t^{*}$ before the competitor. Obviously, the latter implies no equilibrium in pure strategies.

Let's compare the results of the discrete-time model in Section 2 with the more general continuous-time model in Section 4. The former predicts that the channels should 
perfectly overlap their commercial breaks given that they have only two options: perfect coordination or contra strategy. The optimal behavior in the latter model can be either perfect overlap or partial overlap because the set of feasible strategies is continuous. Applying the results of the discrete-time model in the partially overlapping (disequilibrium) case in the continuous-time model, we can say that although perfect overlap is not the optimal strategy, it is still better than no overlap.

\section{Remark on the Cycle Length}

Although the optimal timing of commercial breaks is the primary interest of this paper, it is not the only decision broadcasters have to make. The timing of commercials is in fact the last stage of a game played by the broadcasters. Besides the supply-demand variables; i.e., the price and the amount of commercials, the broadcasters have to decide the number and the length of the breaks in which the commercials will be aired. Recall the set-up of Section 4; i.e., the continuous-time symmetric model with 2 TV broadcasters. Then, the broadcasters also set the length of cycle $T$ and the length of commercial break $L$. In this section the optimal cycle length will be briefly discussed.

Let's assume the Section 4 set-up where the commercial breaks perfectly overlap. ${ }^{7}$ Given that the broadcasters air commercial breaks of length $L$ each cycle of length $T$, they can achieve the same amount of commercial time if they air breaks of length $L / 2$ within a cycle $T / 2$. This is illustrated in Figure 6 .

\footnotetext{
${ }^{7}$ The disequilibrium case where partial overlap is optimal is not analytically feasible. However, the results are likely to be the same.
} 
Audience reach

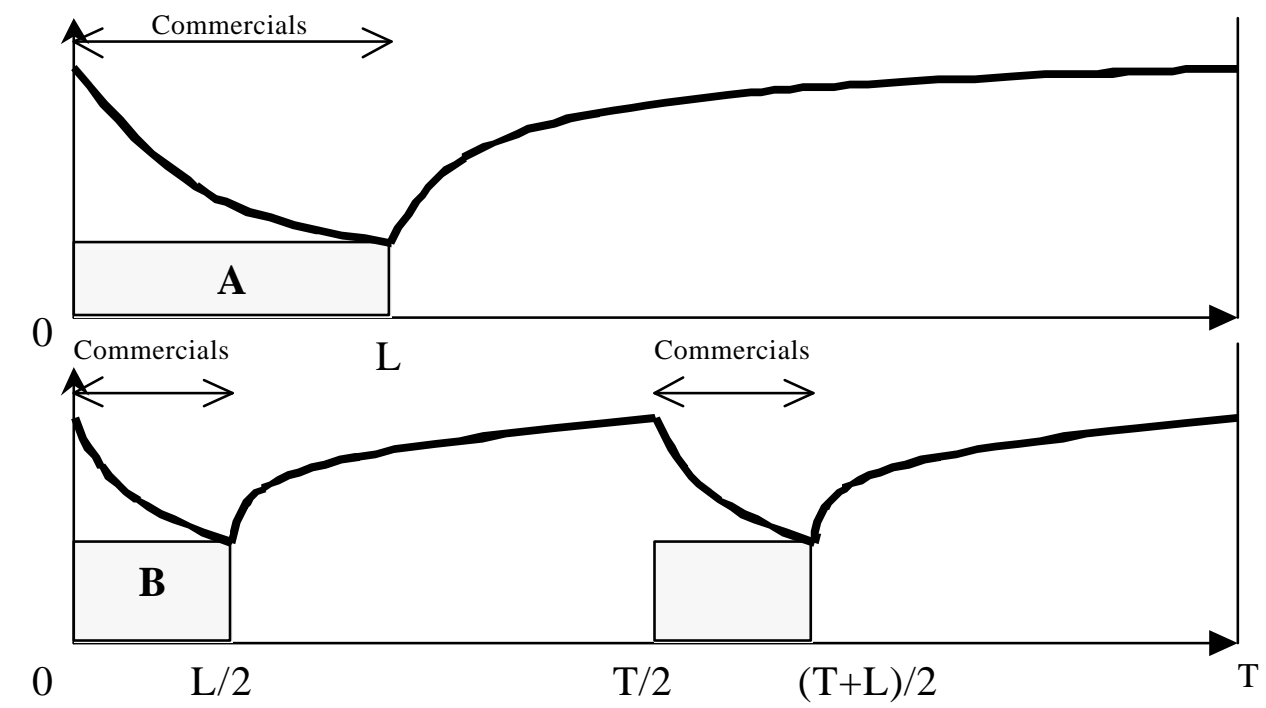

Figure 6

Now let's compare the revenue of the broadcasters $^{8}$ if they choose length $T$ with a revenue in cycle $T / 2$. In terms of Figure 6, we compare area $\mathbf{A}$ with twice that of $\mathbf{B}$. Let $R(p, k, L, T)$ be the revenue of perfect overlapping channels with given parameters. It can be shown that

$$
R(p, k, L, T)-2 R(p, k, L / 2, T / 2)=\frac{L(k-1)\left(e^{\frac{L p}{2}(2+k)}-1\right)\left(e^{-\frac{3 p}{2}(T-L)}-1\right)}{3(2+k)\left(e^{L p(2+k)}-e^{-3 p(T-L)}\right)}<0 .
$$

Hence, cutting the length of the cycle simultaneously to half is profitable for both channels. This result suggests that greater fragmentation of commercials into uniformly distributed very small breaks brings in higher revenue for both channels. However, in reality there are some limitations. The first limitation is the commercial spot itself. It needs some time to have an impact on the viewer; i.e., to communicate the information to

\footnotetext{
${ }^{8}$ Both broadcasters have the same revenue because of the symmetry of the set-up.
} 
the viewer without interruption. The second limitation is the program (e.g., a movie) during which the commercial is aired. The more fragmented the program is, the less enjoyable it is; thus, transition rate $p$ changes while in the analysis $p$ was assumed to be fixed.

In reality we can observe that commercial breaks are fragmented. However, the fragmentation is not infinite and both limitations mentioned above are in effect. The first is natural: no single commercial spot is split into smaller parts. Nevertheless, the spot itself is not the only actual limitation because we can also observe more spots in one commercial break. This grouping occurs in order to not decrease the attractiveness of the program; i.e., the second limitation.

\section{Conclusion}

In this paper I assume that TV viewers switch among channels as if according to a homogeneous Markov process. However, the parameters of the process depend on the type of broadcasting. If there is a commercial break on a particular channel, viewers leave this channel at higher rate than if there is a movie. The broadcasters are aware of this, and thus, they place their commercials in order to maximize their revenue.

The solution to the symmetric model with 2 players in discrete time suggests that broadcasters' optimal strategy is coordination; i.e., they are better off if they air their breaks at the same times.

In the symmetric continuous-time model with two broadcasters, equal rates of switching and a fixed length of commercial breaks, I have shown that the broadcasters will place their commercials to the same or very close times. Moreover, if 
the viewers' sensitivity to commercials is low, the commercial breaks will perfectly overlap; i.e., there is equilibrium in pure strategies in which the broadcasters start and finish advertising at the same times. We have also shown that broadcasters tend to fragment the commercials into more breaks. Nonetheless, they are limited in the extent of fragmentation by the length of one spot and by the displeasure caused to the viewers.

Unfortunately, the extensive formulas of the analytical results heavily restricted the number of questions which were intended to be answered by this model. Calibrating the model using a real data set or simulations run for more general cases are definitely interesting directions for future research on this topic. 


\section{References}

Anderson, S.P. and Coate, S. 2000. "Market Provision of Public Goods: The Case of Broadcasting," mimeo.

Bowman, G. 1975. "Consumer Choice and Television," Applied Economics, 1975, 7, $175-184$.

Epstein, G. S. 1998. "Network Competition and the Timing of Commercials," Management Science, Vol. 44, No.3, March 1998.

Gabszewicz, J., Didier Laussel and Nathalie Sonnac. 1999. "TV-Broadcasting Competition and Advertising," mimeo.

Hendry, David. F. 1992. "An Econometric Analysis of TV Advertising Expenditure in the United Kingdom," in Neil R. Ericsson and John S. Irons, eds. Testing Exogeneity. New York: Oxford University Press, 1994, 275-307.

Last, G. and Andreas Brandt. 1995. Marked Point Processes on the Real Line. The Dynamic Approach. New York: Springer.

Peterman, J. L. "Concentration of Control and the Price of Television," AmericanEconomic-Review, 61(2), May 1971, 74-80.

Spence, M. and Bruce Owen. 1977. "Television Programming, Monopolistic Competition and Welfare," QJE, 2, 103-126. 


\section{Appendix I}

Lemma:

$\mathbf{d}(t)=\left(e^{\mathbf{Q} \cdot t}\right)^{\mathbf{T}} \cdot \mathbf{d}(0)$ is a solution $\mathrm{t}$ o $\mathbf{d}(t)=\mathbf{Q}^{\mathbf{T}} \cdot \mathbf{d}(t)$

Proof:

$\frac{\partial}{\partial t} \mathbf{d}(t)=\mathbf{Q}^{\mathbf{T}} \cdot\left(e^{\mathbf{Q} \cdot t}\right)^{\mathbf{T}} \cdot \mathbf{d}(0)=\mathbf{Q}^{\mathbf{T}} \cdot \mathbf{d}(t) . Q E D$.

Lemma:

$\mathbf{d}(t)=$ V.Diag $\left\{e^{\lambda_{1} \cdot t}, e^{\lambda_{2} \cdot t}, \ldots, e^{\lambda_{n+1} \cdot t}\right\} \cdot \mathbf{V}^{-1} \cdot \mathbf{d}(0)$ is a solution $t$ o $\dot{\mathbf{d}}(t)=\mathbf{Q}^{\mathbf{T}} \cdot \mathbf{d}(t)$

Proof:

Denote $\mathbf{v}_{i}$ as eigenvectors of $\mathbf{Q}^{\mathbf{T}}$ and $\lambda_{i}$ as corresponding eigenvalues. Then,

$$
\mathbf{d}(t)=\sum_{i=1}^{n+1} c_{i} \cdot e^{\lambda_{i} \cdot t} \cdot \mathbf{v}_{i}
$$

where $c_{i}$ are such that $\mathbf{d}(t)$ satisfy the initial condition.

$$
\frac{\partial}{\partial t} \mathbf{d}(t)=\sum_{i=1}^{n+1} c_{i} \cdot e^{\lambda_{i} \cdot t} \cdot \lambda_{i} \cdot \mathbf{v}_{i}=\mathbf{Q}^{\mathrm{T}} \cdot \sum_{i=1}^{n+1} c_{i} \cdot e^{\lambda_{i} \cdot t} \cdot \mathbf{v}_{i}=\mathbf{Q}^{\mathrm{T}} \cdot \mathbf{d}(t)
$$

Hence, it is also a solution to the system of differential equations.

$$
\begin{array}{r}
\mathbf{d}(t)=\left(\begin{array}{llll}
\mathbf{v}_{1} & \mathbf{v}_{2} & \ldots & \mathbf{v}_{n+1}
\end{array}\right) \cdot \mathbf{D i a g}\left\{e^{\lambda_{1} \cdot t}, e^{\lambda_{2} \cdot t}, \ldots, e^{\lambda_{n+1} \cdot t}\right\} \cdot\left(\begin{array}{c}
c_{1} \\
c_{2} \\
c_{n+1}
\end{array}\right) \\
\mathbf{d}(0)=\mathbf{V} \cdot\left(\begin{array}{l}
c_{1} \\
c_{2} \\
c_{n+1}
\end{array}\right) \Rightarrow\left(\begin{array}{c}
c_{1} \\
c_{2} \\
c_{n+1}
\end{array}\right)=\mathbf{V}^{-1} \cdot \mathbf{d}(0) \Rightarrow \mathbf{d}(t)=\mathbf{V} \cdot \operatorname{Diag}\left\{e^{\lambda_{1} \cdot t}, e^{\lambda_{2} \cdot t}, \ldots, e^{\lambda_{n+1} \cdot t}\right\} \cdot \mathbf{V}^{-1} \cdot \mathbf{d}(0)
\end{array}
$$

QED. 


\section{Appendix II}

Lemma:

$$
-4 e^{4 L p}+6 e^{p(2 L(1+k)+3 T)}+e^{4 L p+3 p T}+e^{4 k L p+3 p T}-4 e^{4 k L p+6 p T}<0
$$

\section{Proof:}

Solve the inequality for $k$. First, substitute $x$ for $e^{2 p L k}$ and solve it as a quadratic equation.

$$
\begin{gathered}
x^{2}\left(e^{3 p T}-4 e^{6 p T}\right)+x \cdot 6 e^{p(2 L+3 T)}+e^{p(4 L+3 T)}-4 e^{4 L p}=0 \\
D=36 e^{2 p(2 L+3 T)}-4\left(e^{3 p T}-4 e^{6 p T}\right)\left(e^{p(4 L+3 T)}-4 e^{4 L p}\right)=16 e^{4 L p+3 p T}\left(e^{3 p T}-1\right)^{2} \\
x_{1}=e^{p L} \frac{1-2 e^{-1.5 p T}}{1-2 e^{1.5 p T}} \quad x_{2}=e^{p L} \frac{1+2 e^{-1.5 p T}}{1+2 e^{1.5 p T}}
\end{gathered}
$$

Obviously, $x_{1}<-e^{p L}$ and $0<x_{2}<e^{p L}$. For $x=e^{p L}$ the expression equals $-4 \mathrm{e}^{4 p L}\left(e^{3 p T}-1\right)$ which is negative. Hence, for all $x>e^{p L}$ it must be negative too which means that for all $k>1$ the inequality holds. $Q E D$. 